\title{
Discussion of the Energy-Saving Benefits of Heat Insulating Coating for Building Windows
}

\author{
Jing-Yi Chang ${ }^{1, a^{*}}$, Yean-Der Kuan, ${ }^{2, b}$, Chun-Ching Lan ${ }^{2, \mathrm{c}}$, Hsing-Ju Li ${ }^{2, \mathrm{~d}}$, Yu-Kun Hsu${ }^{2, \mathrm{e}}$, Chih-Yao Chen ${ }^{2, \mathrm{f}}$, En-Ting Shen ${ }^{2, \mathrm{~g}}$ \\ and Kun-Yi Lin ${ }^{1, \mathrm{~h}}$ \\ ${ }^{1}$ Department of Marine Engineering, Taipei College of Maritime Technology, Taipei, Taiwan \\ ${ }^{2}$ Department of Refrigeration, Air-Conditioning and Energy Engineering, National Chi-Yi University of Technology, Taichung, Taiwan
}

\begin{abstract}
Nano transparent heat insulating coating is applied to window glass in this study. The heat insulating coating absorbs thermal radiation, and reduces the thermal radiation transmittance of glass, thus, preventing the building heat load from increasing in summer, or reducing the consumption of heat energy in winter. Therefore, this study will design a scaled down building model room, where heat insulating coating is coated on the inner side of the window glass of the model room, and the thermal radiation isolation effect is tested. Finally, the building energy-saving benefit of outdoor heat insulation in summer and indoor heat preservation in winter is discussed.
\end{abstract}

Keywords: Nano Transparent Heat Insulating Coating, Building Energy-Saving Benefit, Residential Energy Saving Application.

\section{INTRODUCTION}

Taiwan's green building evaluation system (EEWH) with subtropical climate characteristic is the fourth green building evaluation system in the world, as based on ecology, energy saving, waste reduction, and health, including nine major evaluation indices, which are biodiversity, greenery, on-site water retention, daily energy saving, $\mathrm{CO} 2$ reduction, waste reduction, indoor environment, water resource, sewage, and garbage improvement. Among the daily energy saving indices of green buildings, the energy efficient design for the major power consumption of air conditioning and lighting is the key point, and the energy saving evaluation aims at building envelopment energy efficient design, air conditioning efficiency design, and lighting efficiency design.

Generally speaking, about $95 \%$ of a building is made of reinforced concrete, and many office buildings use glass curtain walls, which are two materials of high heat capacity, and are likely to absorb and accumulate solar heat. For good airtightness, poor aeration, and high thermal storage capacity, when the outdoor heat source stops, the building materials still continuously release the accumulated radiant heat, thus, the hot air stays indoors and is unlikely to diffuse, increasing the energy consumption of air conditioning. Therefore, as Taiwan is wet and hot, and the temperature is often higher than $35^{\circ} \mathrm{C}$ in summer, many buildings use all-sided glass external walls; this type of buildings is applicable to high latitude cold places for preserving solar radiation heat in winter, creating the greenhouse effect to warm the rooms. However, when this building engineering is introduced into Taiwan with its subtropical climate, indoor thermal storage increases as a result, the air conditioning load is increased, energy consumption is increased, and the indoor air conditioning power is severely wasted [1-4].

Many scholars have globally studied the thermal characteristics of building glass. Somsak [5] indicated that glass windows have considerable transmittance property, and in strong solar radiation, more radiant heat is absorbed, and thermal comfort is reduced. Ismail [6] used experiments and numerical simulation to study solar radiation heat efficiency on glass windows, and filled the phase change material and air between the double glass. The result showed the filling of phase change material could filter thermal radiation and reduce heat absorption, and the double glass reduced the absorption of radiant energy better than filling with air.

\section{RESEARCH METHOD 2.1 MODEL ROOM DESIGN}

The actual building is assumed as a single dwelling, $6 \mathrm{~m}$ long, $5 \mathrm{~m}$ wide, and $4 \mathrm{~m}$ high wooden house, which is scaled down to a $30 \mathrm{~cm}(\mathrm{~L}) \times 25 \mathrm{~cm}(\mathrm{~W})$ $\mathrm{x} 12 \mathrm{~cm}(\mathrm{H})$ model room constructed of $8 \mathrm{~mm}$ plywood, as shown in Figure 1. However, if the glass thickness of the model room is scaled down, the thickness will be too small, and the model will be difficult to make and analyze. Therefore, this experiment uses the most frequently used minimum thickness of $3 \mathrm{~mm}$ window glass on the market.

\footnotetext{
adio990@gmail.com, ${ }^{\mathrm{b}}$ ydkuan@ncut.edu.tw, ${ }^{\mathrm{c} a s 20549 @ y a h o o . c o m . t w, ~}{ }^{\mathrm{d}}$ seaotter820515@yahoo.com.tw, eqen1112@gmail.com, fmark910i@yahoo.com.tw,

gcaba102171@yahoo.com.tw, kunyi0914@gmail.com
} 


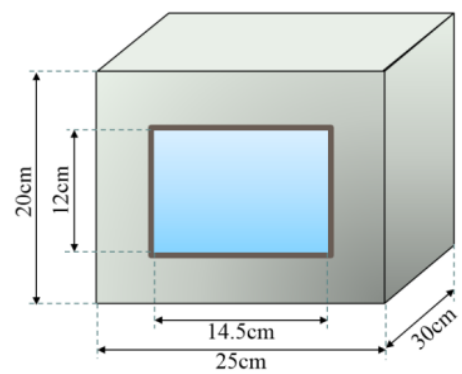

Figure 1 Structural Representation of Model Room

\subsection{EXPERIMENT ON OUTDOOR HEAT INSULATION EFFICIENCY}

This experiment uses a $500 \mathrm{~W}$ halogen lamp, because the radiation wavelength of a halogen lamp is in the range of visible light and near infrared. The irradiation power of solar radiation in this wavelength range is about $90 \%$ of the total power, thus, it is the main source range of solar radiation heat. As shown in Figure 2, the halogen lamp is mounted ahead of the glass window of the model room, with an elevation angle of $30^{\circ}$ and appropriate distance of about $55 \mathrm{~cm}$. The light irradiates the model room to simulate the sunlight source. The heat generated by the halogen lamp enters the room through the glass by radiation, transfer, and convection. Afterwards, the temperature is measured by T-type thermocouple wires, which are mounted on both sides of glass surface to measure the effect of radiation on the temperature of the glass surfaces with and without coating. A sensing point is mounted in the center of the room in order to detect the indoor temperature change, and estimate the energysaving benefit of the coating.

However, the aforesaid experimental results show that the heat storage in the room may result in the greenhouse effect. Therefore, this experiment uses a forced ventilation system to import outside cool air to absorb the heat generated by radiation, in order to discharge the indoor thermal storage, and the temperature change is measured to discuss the building energy-saving benefit of outdoor heat insulation in summer, as shown in Figure 3.

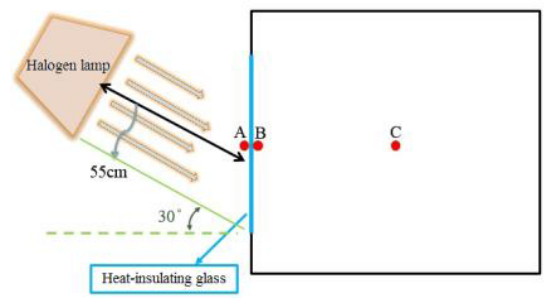

\subsection{EXPERIMENT ON INSULATING EFFICIENCY}

This experiment simulates day and night modes, respectively, in order to observe the effect of heat insulating coating on indoor thermal insulation. The night mode mounting is as shown in Figure 4. The ambient temperature is set as $23^{\circ} \mathrm{C}$, and a $60 \mathrm{~W}$ lamp is mounted in the center of model room as the indoor heating source.

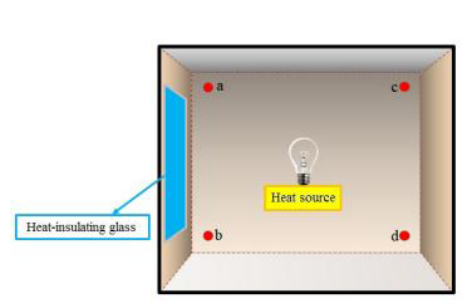

Figure 4 Indoor Insulation in Night Mode Mode Finally, the

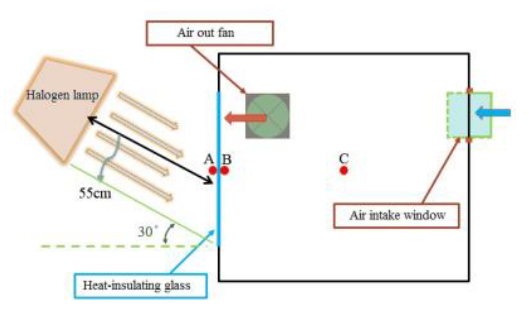

Figure 3 Outdoor Heat Insulation with Ventilation

INDOOR

temperature sensing points are mounted at the four corners of the room to observe the indoor temperature distribution. The day mode mounting is as shown in Figure 5, where the ambient temperature is $23^{\circ} \mathrm{C}$, a $500 \mathrm{~W}$ halogen lamp simulates the sunlight source, and a $60 \mathrm{~W}$ lamp is mounted in the center of model room as the indoor heating source. The temperature sensing points are mounted at four corners of the room in order to observe the indoor temperature distribution, and discuss the insulating efficiency of glass with and without coating.

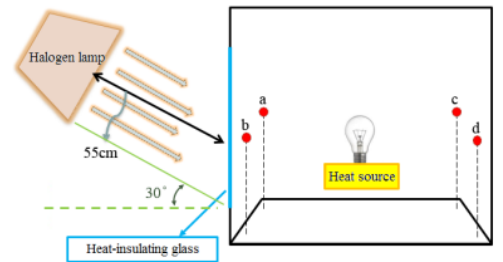

Figure 5 Indoor Insulation in Day 


\section{RESULTS AND DISCUSSION \\ 3.1 EXPERIMENTAL RESULT OF OUTDOOR HEAT INSULATION EFFICIENCY}

As shown in Figure 6, according to glass surface temperature measuring points $\mathrm{A}$ and $\mathrm{B}$, the temperature of the coated glass surface is apparently higher than the uncoated surface, the external surface temperature is 4.5 ${ }^{\circ} \mathrm{C}$ higher, and the inner surface temperature is $3.6^{\circ} \mathrm{C}$ higher, meaning the radiant heat energy of the halogen lamp is absorbed by the heat insulating coating, the radiant heat energy is accumulated in the glass, and the temperature of the glass rises; Meanwhile the radiant heat energy is prevented from entering the room, and the radiation transmittance of glass is reduced. According to temperature measuring point $\mathrm{C}$ at the center of the room, the indoor temperature with coating is $0.7^{\circ} \mathrm{C}$ lower than

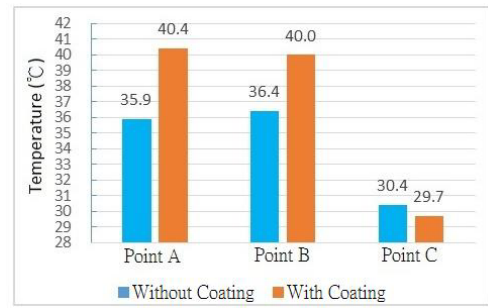

Figure 6 Temperatures Measuring Points

\subsection{EXPERIMENTAL RESULT OF INDOOR INSULATING EFFICIENCY}

Figure 8 shows indoor temperature night-time distribution, the temperatures at temperature measuring points $\mathrm{a}$ and $\mathrm{b}$ close to the glass window indoors are lower than the temperatures at farther temperature measuring points $\mathrm{c}$ and $\mathrm{d}$ by $0.3^{\circ} \mathrm{C} \sim 0.7^{\circ} \mathrm{C}$, meaning the glass has higher heat loss than the wood wall, and the indoor temperature falls. The temperatures at four measuring points in the room are averaged, the indoor average temperature without coating is $33.2^{\circ} \mathrm{C}$, the indoor average temperature with coating is $33.7^{\circ} \mathrm{C}$, meaning that the heat insulating coating can effectively reduce the heat loss of glass, and increase the indoor average temperature by 0.5 ${ }^{\circ} \mathrm{C}$. When the heating efficiency is about $1.5 \%$, air conditioning power consumption can be reduced by $3 \%$.

According to the aforesaid experimental results, this coating can effectively reduce the heat loss of glass. As shown in Figure 9, during the day, the temperature is that without coating, the cooling efficiency is about $2.3 \%$, and the air conditioning power consumption is estimated to be reduced by $4.2 \%$.

According to temperature measuring point $\mathrm{C}$ at the center of the room, as shown in Figures 6 and 7, when the model room uses a ventilation mechanism, the indoor temperature is reduced by $4.3^{\circ} \mathrm{C} \sim 4.5^{\circ} \mathrm{C}$, the temperature of the glass surface without heat insulating coating is reduced by $2.2^{\circ} \mathrm{C} \sim 5.4^{\circ} \mathrm{C}$, and the temperature of the glass surface with heat insulating coating is reduced by $9.5^{\circ} \mathrm{C}$ $\sim 10.2^{\circ} \mathrm{C}$, meaning this mechanism can effectively remove the thermal storage from the room and glass, and the glass surface with a coating has larger temperature drop, meaning the coating has good convection heat sinking. The heat insulating coating and ventilation mechanism can reduce the indoor temperature by $5^{\circ} \mathrm{C}$, the cooling efficiency is about $16.4 \%$, and the air conditioning power consumption can be reduced by $30 \%$.

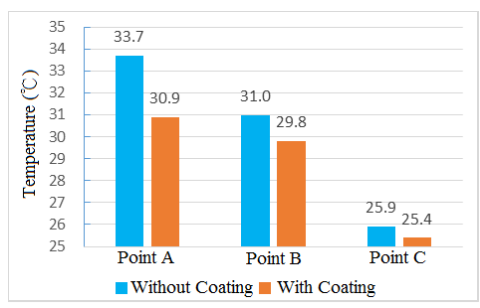

Figure 7 Temperatures Measuring Points

higher near the glass window indoors, meaning the outdoor and indoor radiant heat is absorbed in the glass, and the glass temperature rises, thus, indirectly influencing room temperature. The temperatures at temperature measuring points $\mathrm{a}$ and $\mathrm{b}$ near the glass window indoors are higher than the temperatures at points $\mathrm{c}$ and $\mathrm{d}$ on the opposite side. As the glass window is irradiated by the halogen lamp, the temperature of the glass window with coating is higher than that without coating, because the coating absorbs radiant heat, and the loss of the indoor heat source is reduced. The temperatures at the four measuring points indoors are averaged, the indoor average temperature without coating is $34.4^{\circ} \mathrm{C}$, the indoor average temperature with coating is $36.1^{\circ} \mathrm{C}$, the coating increases the indoor temperature by $1.7^{\circ} \mathrm{C}$, the heating efficiency is about $4.9 \%$, and the air conditioning power consumption can be reduced by $10.2 \%$. Therefore, the thermal insulation effect is excellent in the daytime. 


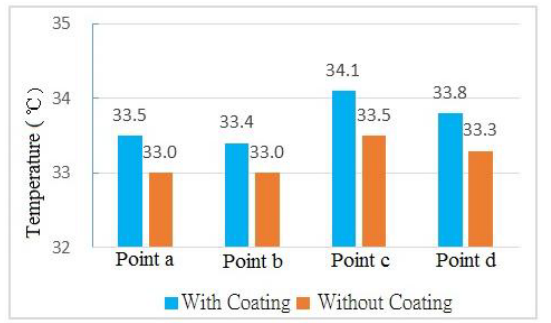

Figure 8 Indoor Temperatures at Night

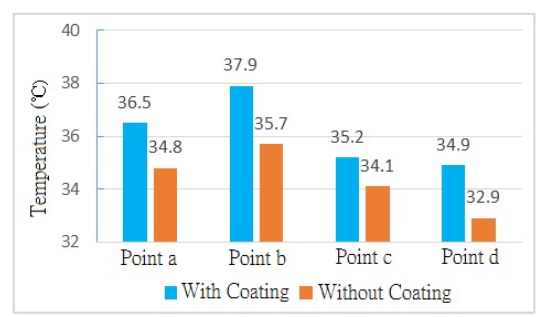

Figure 9 Indoor Temperatures at Daytime

[3] M. Rubin. 1982. "Solar Optical Properties of Windows," Journal of Energy Research., 6:123-133.

[4] M. Rubin. 1982. "Calculating Heat Transfer Through Windows," Journal of Energy Research., 6:341-349.

[5] S. Chaiyapinunt, and B. Phueakphongsuriya. 2005. "Performance Rating of Glass Windows and Glass Windows With Films in Aspect of Thermal Comfort and Heat Transmission," Energy and Buildings., 37:725-738.

[6] K. A. R. Ismail, and J. R. Henriquez. 2001. "Thermal Effective Windows With Moving Phase Change Material Curtains," Applied Thermal Engineering., 21:1909-1923.

[7] http:// www.daikin.co.jp and the air conditioning power consumption is reduced by $3 \%$. The heating efficiency is about $4.9 \%$ in the daytime, the air conditioning power consumption is reduced by $10.2 \%$; and the air conditioning power consumption is reduced by $6.6 \%$ daily.

4. As the radiation frequency of a halogen lamp is lower than the solar radiation frequency, and the glass thickness is $3 \mathrm{~mm}$ in this study; whereas, the glass thickness for actual buildings is mostly larger than $5 \mathrm{~mm}$ or $7 \mathrm{~mm}$, the actual energy-saving efficiency can be higher.

\section{Acknowledgements}

This paper is the project NSC102-2622-E-167018-CC3 of Ministry of Science and Technology. Thanks to the Ministry of Science and Technology for supporting this project.

\section{REFERENCES}

[1] G. Alvarez, M. J. Palacios, and J. J. Flores. 1999. “A test method to evaluate the thermal performance of window glazings," Applied Thermal Engineering ., 20:803-812.

[2] A. Joudi, H. Svedung, M. Cehlin, and M. Ronnelid. 2013. "Reflective coatings for interior and exterior of buildings and improving thermal performance," Applied Energy ., 103:562-570. 